\title{
DIFFUSE MULTIPLE CYSTIC LESIONS IN THE BRAIN
}

\author{
Anjali Bharani. \\ Department of Paediatrics, Mahatma Gandhi Memorial Medical College and M. Y. hospital, Indore, Madhya \\ Pradesh, India.
}

\author{
KEYWORDS \\ Disseminated cysticercosis, cysticercal encephalitis, T. solium
}

\author{
ARTICLE HISTORY \\ Received 18 April 2020 \\ Accepted 12 May 2020
}

\begin{abstract}
A 10-year-old female child presented with fever, irritability, altered sensorium for 20 days and inability to speak for 15 days. There was no contact with a patient suffering from tuberculosis (TB). On examination, she was febrile, disoriented, had hypertonia with brisk deep tendon reflexes along with left sided upper motor neuron type facial palsy and meningeal irritation. Other systems were normal. Investigations revealed normal cerebrospinal fluid (CSF) analysis, normal $X$-ray chest, normal stool examination and negative Mantoux test. HIV serology also was negative. MRI brain showed multiple intra-axial, extra-axial, extracranial hyperintense cystic lesions with intralesional hypointense foci (cyst with dot), involving bilateral cerebral hemispheres (capsule-ganglionic region), thalamus (Figure 1) and brainstem, bilateral cerebellar hemispheres, bilateral muscles of mastication, bilateral extraocular muscles, tongue, neck muscles, upper limb muscles (Figure 2). Multiple foci of calcification were also noted. Peripheral enhancement was seen on post contrast scan. Ophthalmic evaluation did not show any intra-ocular involvement.
\end{abstract}

\section{What is the likely diagnosis?}

Disseminated cysticercal encephalitis and myocysticercosis. Cysticercosis is an infection caused by the invasive intermediate stage of parasite (tapeworm) Taenia Solium which has special tropism for the central nervous system. The risk of cysticercosis may be the same for individuals who eat or do not eat pork, because the intermediate form may be acquired by ingestion of food or water contaminated with eggs of T. Solium ${ }^{1}$ Seizures are the presenting feature in up to $70 \%$ of the cases, however it should be suspected in any child coming with any neurologic, cognitive or personality involvement who is residing in an endemic area. ${ }^{2}$ Neurocysticercosis can be solitary, multifocal or disseminated and may be classified as parenchymal, intraventricular, meningeal, spinal or

CONTACT Dr Anjali Bharani (Associate Professor)

Email: dr.anjalibharani@gmail.com

Address for Correspondence: Dr Anjali Bharani (Associate Professor), Department of Paediatrics, Mahatma Gandhi Memorial Medical College, and M. Y. Hospital, Indore, Madhya Pradesh, India.

(C)2020 Pediatric Oncall
Figure 1. MRI Brain (T2 weighted) transverse section showing diffuse multiple cystic lesions intra-axial and extra axial involving bilateral cerebral hemispheres and basal ganglia and meninges (white arrow)

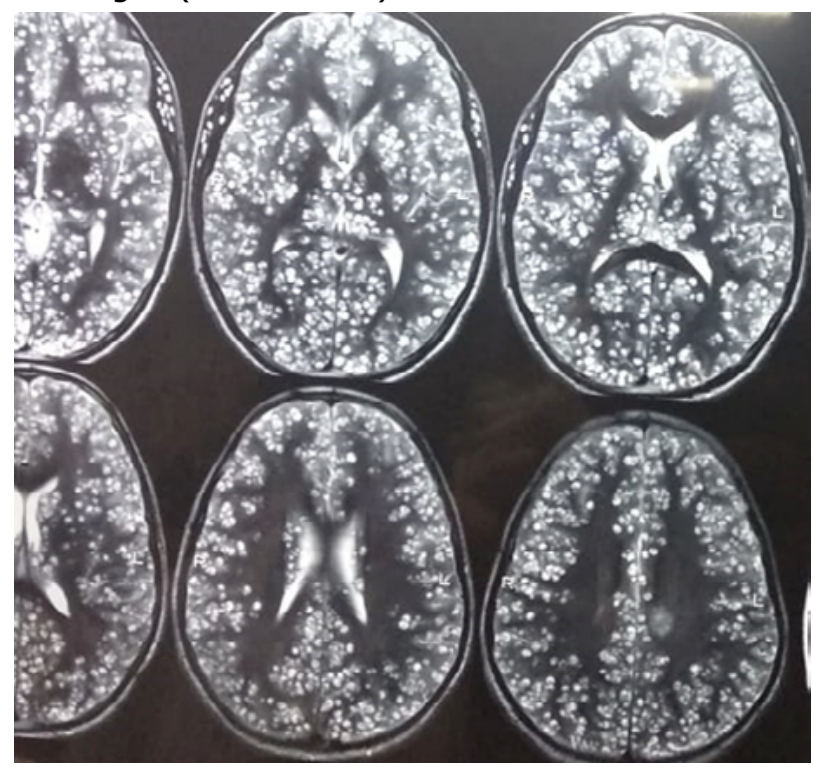

ocular on the basis of anatomic location and radiologic findings. Parenchymal forms mainly present with seizure while extra parenchymal form with features of hydrocephalus, raised intracranial pressure or other mass effects. ${ }^{3}$ Outside the CNS (extra neural)heavy infections may involve the skeletal muscles or the heart muscles leading to myositis or carditis. ${ }^{2}$ Cysticercal encephalitis is a rare presentation of the disease accounting to only $0.3 \%$ of all neurocysticercosis cases characterized by multifocal parenchymal cysts, perilesional inflammation and diffuse cerebral edema. ${ }^{4}$ Neuroimaging in the form of MRI is the most important diagnostic tool which gives information of the location and viability of cysts and associated inflammation. The protoscolex seen within the cyst provides the pathognomonic sign of cysticercosis. ${ }^{5}$ Management of the patient depends upon the clinical presentation. Most patients coming with seizures and signs of raised intracranial tension can be successfully treated with anti-convulsant and anti-oedema measures in the form of steroids. ${ }^{6}$ Antiparasitic therapy in the form of albendazole should be very cautiously used in 
Figure 2. MRI Brain sagittal (T1) and coronal sections (T2) showing diffuse multiple cystic lesions involving cerebellum, tongue (white solid arrow), extra-ocular muscles and neck muscles (white dotted arrow)

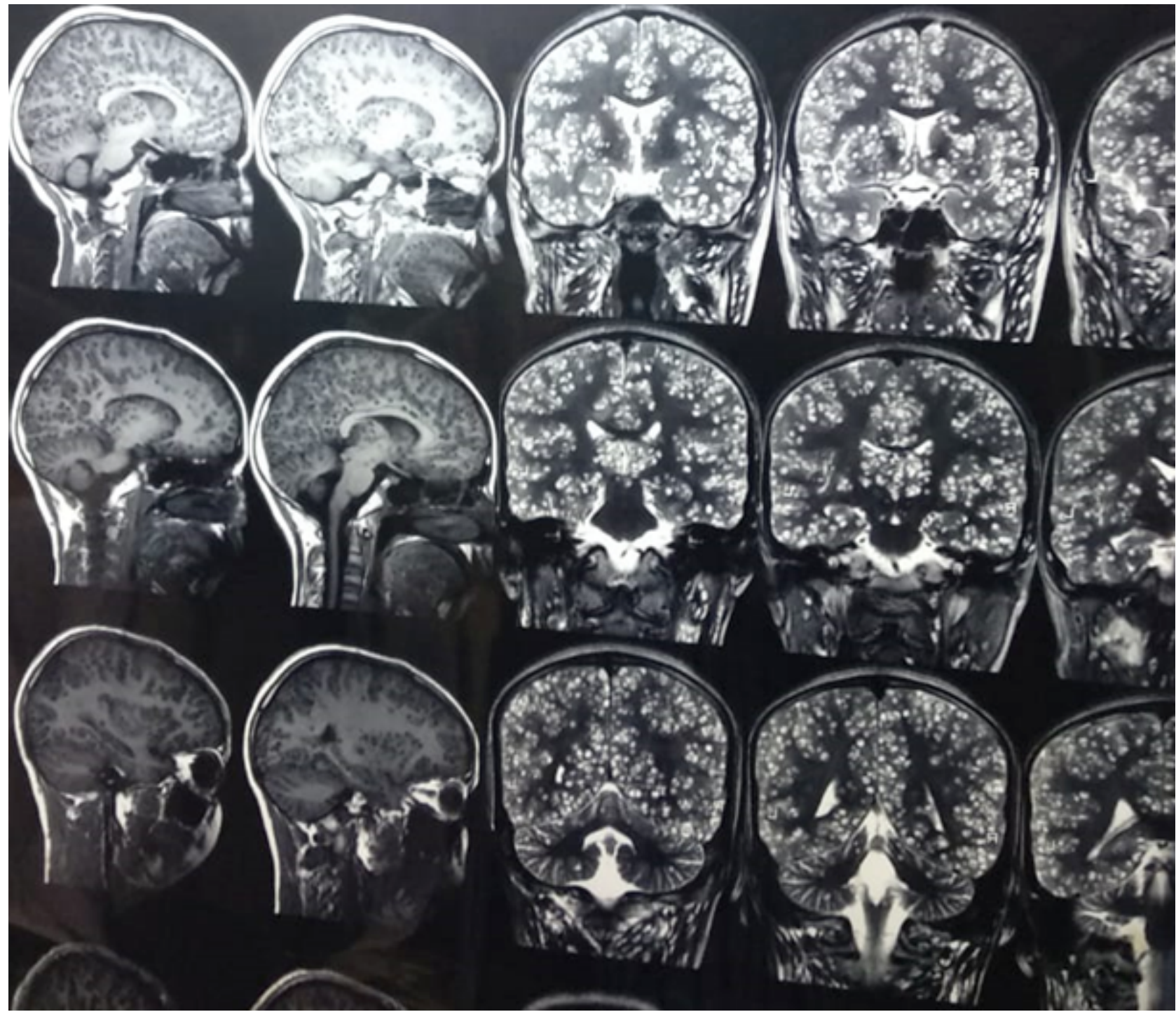

neurocysticercosis because of high risk of exacerbation of neuronal damage, oedema and consequent complications secondary to increased inflammation around the degenerating cyst. ${ }^{6}$ Hence it should always be used in combination with an anti-inflammatory agent, usually corticosteroids. ${ }^{7}$ Albendazole therapy is contraindicated in cysticercal encephalitis as it may exacerbate inflammatory response and increase the risk of cerebral oedema and subsequent transtentorial herniation. ${ }^{7,8}$ Steroids are the most effective drugs in the management of cysticercal encephalitis due to their anti-inflammatory and antioedema properties. ${ }^{9}$ Our patient was treated with injectable dexamethasone $(0.2 \mathrm{mg} / \mathrm{kg}$ dose thrice a day) for 5 days then oral prednisolone $2 \mathrm{mg} / \mathrm{kg} /$ day and anti-edema measures (intravenous mannitol $2 \mathrm{ml} / \mathrm{kg} /$ dose 8 hourly) along with prophylactic oral valproate $(20 \mathrm{mg} / \mathrm{kg} /$ day in two divided doses). Albendazole was deferred in view of many active lesions. She showed some improvement in fever and sensorium, but neck rigidity persisted. Attenders were not willing for further hospital stay and took discharge against medical advice after 7 days of hospital stay.

\section{References:}

1. World Health Organization (WHO). Taeniasis/ Cysticercosis 2019. Available at URL: https://www.who.int/news-room/ fact-sheets/detail/taeniasis-cysticercosis. Accessed on 23 April 2020

2. Blanton R. Cysticercosis. In: Kliegman RM, Stanton B, St. Geme J, Schor NF, Behram RE (eds). Nelson textbook of Pediatrics. 19th ed. Philadelphia. Elsevier.2011: 1234-1237

3. Garcia HH, Nash TE, Del Brutto OH. Clinical symptoms, diagnosis, and treatment of neurocysticercosis. Lancet Neurol. 2014; 13:1202-15

4. Rangel R, Torres B, Del Bruto O, Sotelo J. Cysticercotic encephalitis: a severe form in young females. Am J Trop Med Hyg. 1987;36: 387-92.

5. Aung AK, Spelman DW. Taenia solium Taeniasis and Cysticercosis in Southeast Asia. Am J Trop Med Hyg. 2016;94:947-954.

6. Singhi P, Saini AG. Pediatric Neurocysticercosis. Indian J Pediatr. 2019; 86: 76082 
7. Garg RK, Potluri N, Kar AM, Singh MK, Shukla R, Agrawal A, et al. Short course of prednisolone in patients with solitary cysticercus granuloma. J Infect. 2006; 53:65-9.

8. Singhi P. Neurocysticercosis. Ther Adv NeurolDisord.
2011;4:67-81.

9. Garcia HH, Evans CA, Nash TE, Takayanagui OM, White AC, Botero $D$, et al. Current consensus guidelines for treatment of neurocysticercosis. Clin Microbiol Rev. 2002; 15:747 